\title{
On-Shelf Availability in Retailing
}

\author{
Rahul Moorthy \\ Student \\ Mukesh Patel School of \\ Technology Management and \\ Engineering, NMIMS University
}

\author{
Swikriti Behera \\ Student \\ Mukesh Patel School of \\ Technology Management and \\ Engineering, NMIMS University
}

\author{
SauravVerma \\ Assistant Professor - IT \\ DeptMukesh Patel School of \\ Technology Management and \\ Engineering, NMIMS University
}

\begin{abstract}
Ensuring high On-Shelf Availability (OSA) is essential for retailers today. It is a measure of retailer performance. Out-of Stock is a major problem in retailing, as it leads to lost sales and decreased consumer loyalty. The term 'Out-of-Stock' is used to describe a situation where a consumer does not find the product on the shelf, at the time he/she wishes to purchase it. The root causes leading to OOS include inventory inaccuracy, unexpected high demand, restock frequency and poor shelf monitoring.

Yet, the possibilities for detecting and measuring an out-of shelf situation are limited, mainly involving visual shelf audits. Hence, the existence of an automatic method for detecting the products that are not on the shelf, would be valuable, offering an accurate view of the shelf availability to the store manager. The proposed solution, is a real-time application connected to a camera device that monitors the onshelf availability of products and sends alerts to the store manager when products go out of shelf or are misplaced. The proposed solution, compared to the existing solutions, is cost effective, easy to implement and easy to use.
\end{abstract}

\section{Keywords}

OSA (On shelf Availability), OOS (Out of Stock), Retail, RFID (Radio Frequency Identification).

\section{INTRODUCTION}

On-Shelf Availability (OSA) is the measure of the amount of products available in saleable condition to a customer, at the place he expects and at the time he wants to buy the product. On average, retailers spend $5 \%$ of sales on logistics. The largest part of these costs are caused on the store level by inventory handling (38\%) and holding (7\%) [1]. Thus, improving in-store inventory management is essential to retailer profitability. Maintaining OSA or reducing Out-ofStock (OOS) help in improving in-store inventory management and are hence indicators of retailer performance. Out-of-stocks (OOS), a counterpart to OSA, occur when a consumer at a retail outlet arrives at the shelf and the specific product they are seeking is not available [2].

There are several reasons for OOS. The number of retail items continues to proliferate $(25,000$ in 2001 versus 35,000 in 2003 for an average grocery store, according to the Food Marketing Institute website (www.fmi.org), which automatically reduces the storage capacity per item on shelves or in storerooms. This reduction has coincided with a decrease in storeroom areas by many retailers that want to gain additional selling space, as well as with the adoption of just-in-time procedures to reduce retailer inventory costs [3]. Another major cause for shelf OOS is phantom inventory. Phantom inventory occurs when the inventory management system shows that a particular product is available even when that product is not actually present. This can be caused if a product is damaged or stolen from the shelf, if the product is recalled or if the product is still in the customer's cart. Figure 1 outlines the root causes of OOS.

When a product is not found on the shelf, there are two possibilities, either the product is still in the customer's cart and not sold yet or the product is not in the customer's cart, but sold out. When the product is in customer's cart, the reasons for OOS include, delay in shelf replenishment, misplaced product or product removed from shelf due to damage, theft, recall etc. [4]. When the product is not in the customer's cart i.e. the product is sold out, the reasons for OOS include:

1. Product not ordered by the store due to inventory inaccuracies. For example, stock is incorrectly assumed to exist [4].

2. Inadequate stock ordered due to incorrect estimations of volume or incorrect stock ordered.

3. Delay in delivery of the product ordered by supplier due to insufficient stock.

$25 \%$ of the OOS conditions are shelf-OOS [5]. Shelf-OOS is the condition when the product is available in the inventory, but not present in the shelf when the customer was looking for it.

This situation is particularly frustrating since the order forecast may have been correct, and the supply and delivery functions executed appropriately. However, due to execution in the store, for some reason the product didn't make it the final 50 meters so it could land in the shopper's cart [5].

When an OOS condition occurs, customer reactions are as follows [6]:

1. $31 \%$ buy the product they need, but elsewhere (different store or online)

2. $26 \%$ buy a different brand

3. $19 \%$ still buy the same brand but a different variant/size/flavour

4. $15 \%$ buy the product at a later date

5. $9 \%$ buy nothing. 


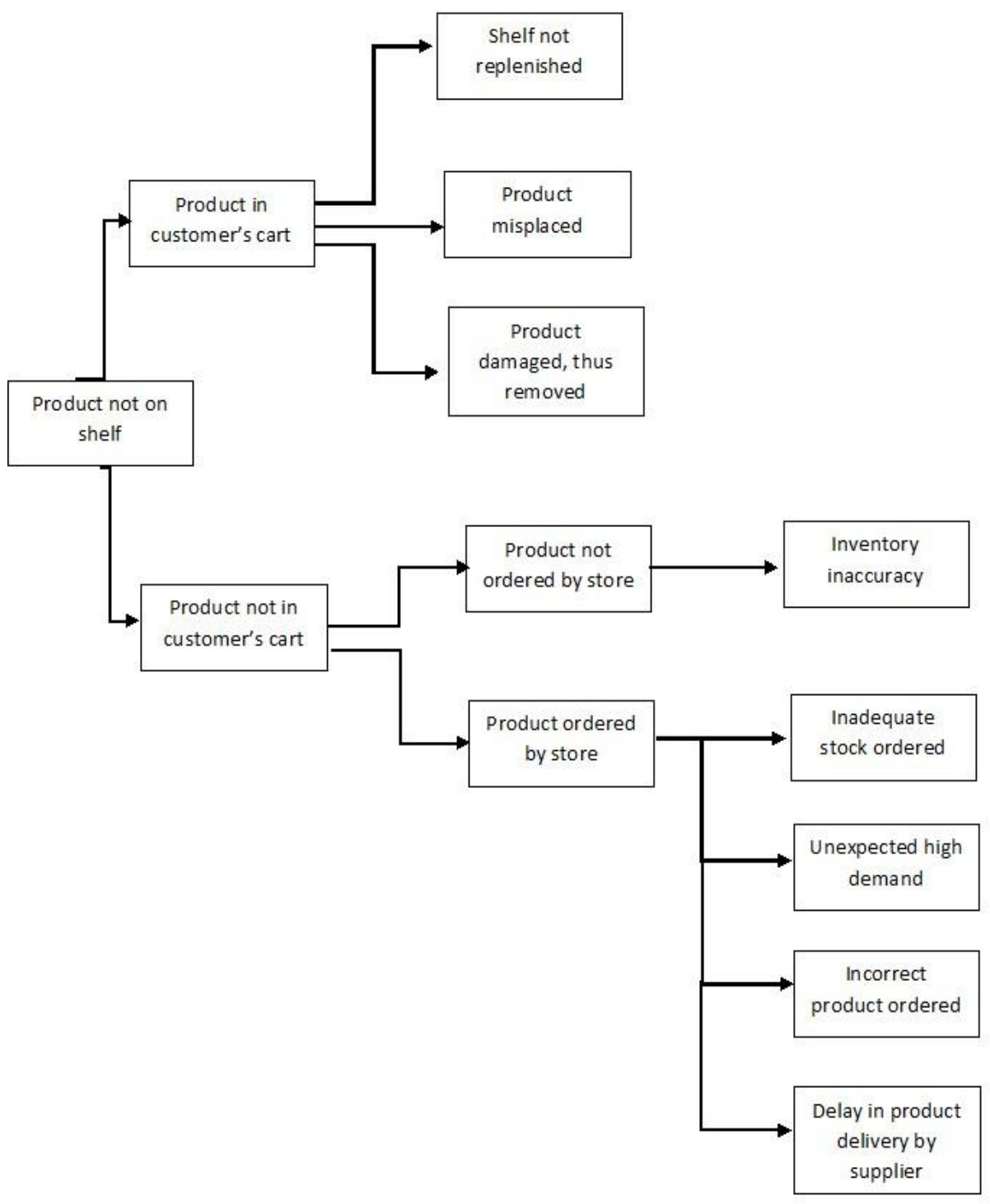

Fig 1: Reasons for OOS

$9 \%$ of the customers who buy nothing, lead to a loss of EUR 4 Billion [7]. If the OOS condition occurs repeatedly, the customer would be forced to permanently switch to a different store, considering the wide range of choice available to him today. When a "loyal" family turns its back on a given store, the weekly revenue loss comes to around EUR 150. Over a 20year period, that adds up to EUR 150,000 in lost revenues [7]. Also, $20 \%$ of all OOS remain unresolved for 3 days [6].This adversely impacts retailer performance and profitability.

For manufacturers, a 3\% increase in OSA equals a $1 \%$ increase in sales and for a retailer a $2 \%$ increase in OSA equals a $1 \%$ increase in sales [6]. Therefore, retail stores must ensure high OSA to retain loyal customers. Piling up the inventory with extra products is not a feasible solution as it can lead to more losses due to wastages. Also, even if a product is available in the inventory, there is a possibility it might not reach the shelf due to inefficient shelf management.

\section{CURRENT SCENARIO}

Several methods are being adopted by retailers today to ensure high OSA of products. One of them is store audits which involve visual inspection of shelves. The auditor physically assesses each shelf and replenishes empty ones. But such a method is labour intensive and does not provide a reliable assessment of OOS as firstly, the assessment depends upon the auditor's time of visit, which is arbitrary. An item available at 2:00 p.m. may be missing at 5:00 p.m. Secondly, the observations, because they are by nature instantaneous, cannot assess the duration of an observed OOS. Whereas some items missing at 2:00 p.m. may be back on the shelf at 5:00 p.m. the same day, others will be back only two days later, which implies a greater level of inconvenience to consumers and increased sales losses [3]. Thirdly, in countries where labour is expensive, this method may not be feasible. Lastly, this method is susceptible to human errors and inaccuracies of measurement as it involves manual human observations. 
Technology too has played an important role in improving the OSA of a product. Barcodes are being widely used by retailers all over the world to obtain product and shelf information. The world's largest retailer, Walmart, and dozens of other well established retailers are making use of RFID (RadioFrequency Identification) technology to improve OSA. The current technological solutions that help to improve OSA shall be discussed in the further sections. status of the shelf. A 2011 survey indicated that more that more than 14 million mobile users had scanned a QR code, and that nearly 40 percent of them had done so from a retail store [17].

Use of QR codes requires building mobile application, which would have an inbuilt $\mathrm{QR}$ code reader. The QR codes are installed on each shelf. If a customer finds the shelf to be empty he/she can use the mobile application to scan the QR code and also obtain product details.

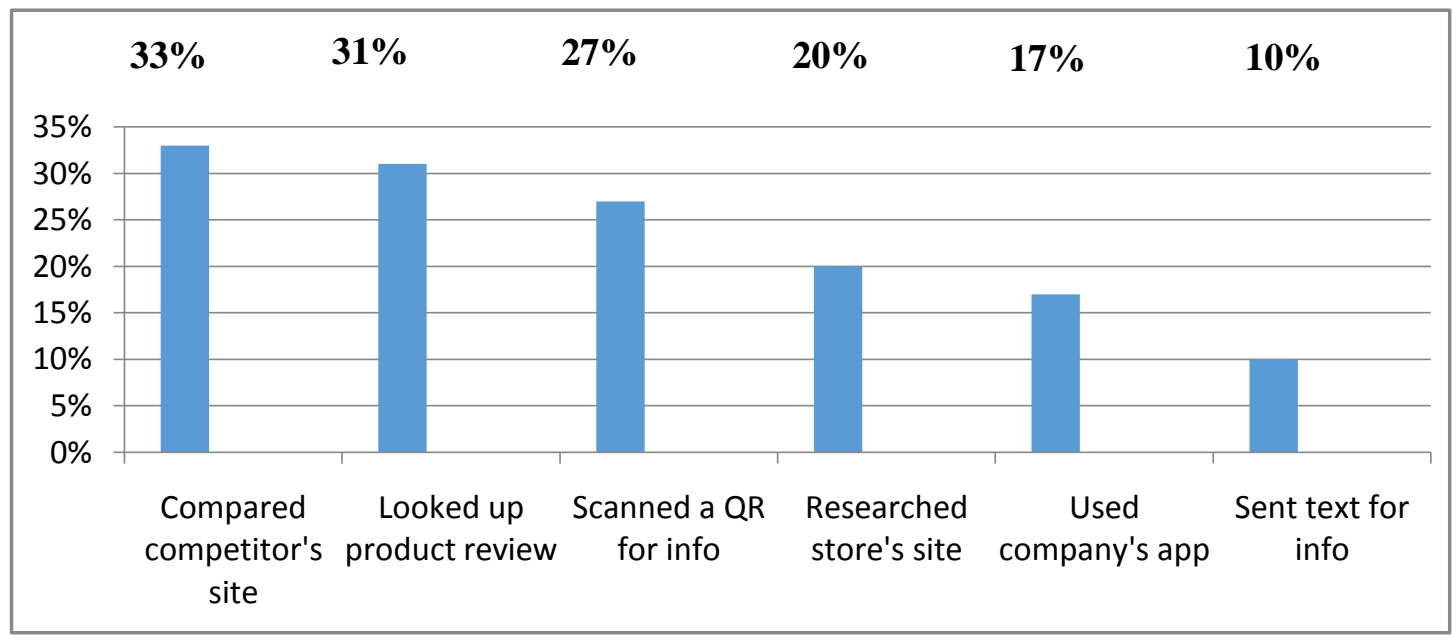

Fig 2[16]: Activities of smartphone owners while in store

\subsection{Mobile Apps}

Thanks to the internet-equipped smartphones and the availability of Wi-Fi connectivity in most retail stores, customers are increasingly using their smartphones for checking prices and reviews, while inside a retail outlet. Research shows that $80 \%$ of smartphone owners always or often have their phones with them while shopping [16].

One-third (33\%) of those customers have used their device to lookup a product on a competitor's site while $20 \%$ have researched the store's own website.

Though this may seem like a small number, but as smartphones become increasingly prevalent this number is likely to increase [16]. Due to the proliferation of smartphones, retailers can use it as a means to manage OSA of products. One way is to develop an app for the retail store, which the customers can use to directly communicate with the store managers, regarding unavailability of any product.

If the customer wants to purchase a particular product but finds the shelf empty, he can use the retail store app to photograph the current status of the shelf. This image would then be updated in the database along with an alert being sent to the store manager. The store manager can thus make that particular product available at the billing counter so that the customer need not go back to the shelf to collect it and at the same time the store manager can replenish that shelf.

\subsubsection{QR Codes}

QR codes or Quick responsive codes are specialized version of a 2D barcode which can be used to transfer data. This QR code could link to a website, send a text message or simply display a message to the store manager regarding the current
This would internally alert the store manager via email which he/she can access using his smartphone.

\subsubsection{Disadvantages}

This method is too customer centric. It requires the customer to take the efforts to scan the QR code of the shelf from which the product he is looking for is missing, in order to alert the store manager. A customer would rather prefer purchasing the product from a different store or not purchasing the product at all.

\subsection{RFID}

RFID has been identified as one of the most important technologies of the 21 st century because it allows for real-time tracking of objects or products within the supply chain [8]. RFID is a unique ID- identification system. This system consists of three necessary elements. These are tags, readers and the software necessary to link RFID components to a larger information processing system [9]. The RFID tags contain a small chip and antenna attached to them which are implanted on individual products, thus giving them a unique identity and making it possible to identify and control them throughout the distribution chain. These tags store several information relating to the product on which they are implanted and are powered by the radio frequency signals emitted from the RFID readers which are handheld or fixed devices. The reader sends out electromagnetic waves, and a magnetic field is formed when the signal from the reader "couples" with the tag's antenna. The unpowered RFID tag draws its power from this magnetic field, and it is this power that enables the tag to send back an identifying response to the query of the RFID reader. When the power to the silicon chip on the tag meets the minimum voltage threshold required to "turn it on," the tag then can respond to the reader through the same radio frequency (RF) wave. The reader then converts the 
tag's response into digital data, which the reader then sends on to the information processing system to be used in management applications [9]. Use of RFID tags help to improve inventory accuracy, improve OSA and eliminate OOS.A fixed RFID reader stationed between the back room and the sales floor can track the movement of merchandise, and employees can use handheld readers to take daily inventory of items on store shelves and racks [10].Thus products on the shelves can be counted and empty shelves can be immediately replenished. It also prevents potentially faulty or spoiled products from ending up in the hands of consumers [11]. The appeal of RFID technology lies in its capability to allow retailers to know the exact location and quantity of inventory without conducting time consuming counts [12]. Thus helping retailers to fulfil customer demand by ensuring that inventory is at the right place at the right time in the right amount. RFID is a better technology as compared to QR Codes as it has better durability and stores considerable amount of information about a product. Also, QR codes need to be in the line of sight to be read by scanner; but it is not required in case of RFID [14].

\subsubsection{Disadvantages}

Presently, RFID technology is expensive and the price of RFID tags has traditionally been a significant obstacle to its widespread deployment in SCM (Supply Chain Management) [15]. Also, with an RFID tag, you cannot read just one tag at a time as you can with a QR code. The reader will scan all the tags it picks up in range at once. Tagging is also not simply a matter of attaching RFID tags to items.

One of the major issues with RFID is privacy. There is a possibility that after a product is purchased, it may continue to be tracked, thus revealing the customer's location and other information.

\subsection{Weighted Sensor Shelves}

The system consists of a weight-sensing mat integrated with an RFIDreaderand a ZigBee transceiver (A device that both transmits and receives radio waves).

The mats, which are placed on a store's shelves, are designed to detect changes in the weight of products stacked on top of them, though that sensitivity can be adjusted according to the type of product.

The mat's sensors can not only measure the amount of weight on top of it, thereby enabling the back-end software to calculate the quantity of products, but also detect where the products are located on the mat, based on the level of pressure exerted on those sensors.

If the shelf needs to be restocked, the system could detect that status and send a text message or e-mail to a staff member's smartphone to take a corrective action.

\subsubsection{Disadvantages}

The following are the disadvantages of using Weight sensor shelves:

- High cost of installation of weight sensors on shelves.

- If the product is too light, weight sensor may not sense it at all.
- Weight sensor shelves can only determine if a particular shelf is empty or the count of products on a shelf. But they cannot determine whether a product has been misplaced.

\section{PROPOSED SOLUTION}

The solution proposed involves real time monitoring of the shelves which includes a video streaming/ camera device and an image processing tool. The front end product images e.g.

Kellogg's cereals are captured and stored as reference images. The products are then arranged on a shelf. Images from the video stream can be analysed using an image processing tool and number of facings are detected and counted. Once a product is removed, the application identifies the same and states it as no longer available. If no product is detected on the shelf, an alert is sent to the store manager to replenish the shelf.

This technique also solves the problem about a product being misplaced to another shelf. The stored product images and the captured shelf image are then matched, to determine the presence of a product on the shelf. If it's not detected, then an alert is generated and is sent to the designated person or store manager. The aim of the application lies on processing the captured image using an image processing tool.

\subsubsection{Advantages}

As stated earlier, the commonly available solutions are use of smartphones, use of QR codes and deploying weight sensor shelves. There are significant drawbacks such as in case of smartphones and scanning of QR codes, the customer has to photograph the current status of the shelf or scan the QR code using the retailer's mobile application. This would send an alert to the store manager.

This kind of a solution is too way customer centric, i.e. most of the work is done by the customer. If the customer is not too brand obsessed, he/she could just pick up the same product of a different brand without waiting for the shelf to be replenished. In case of the weight sensor shelf, it cannot determine misplaced products i.e. products deliberately kept on other shelves, as it just sends alerts based on the current weight of the shelf. Also the sensors use RFID tags which are expensive to install and maintain. Hence the proposed solution automates the monitoring of the shelves in a cost effective manner. It aims at, both, detecting sold products as well as detecting misplaced products.

\section{CONCLUSION}

This proposed solution aims at solving OOS condition in retailing as it is a key performance indicator and a measure of customer loyalty and satisfaction. It involves real-time shelf monitoring. The existing solutions for shelf-monitoring are either expensive or labour intensive. The basic idea of the proposed solution is to overcome the need for labour in a cost effective manner.

The basic idea of the proposed solution is to overcome the need for labour in a cost- effective manner. The system can be installed at minimal costs, allowing the store manager to keep a check on every shelf in real-time. An email notifying the store manager about misplaced or missing products makes the task of maintaining on-shelf availability easier for him. 


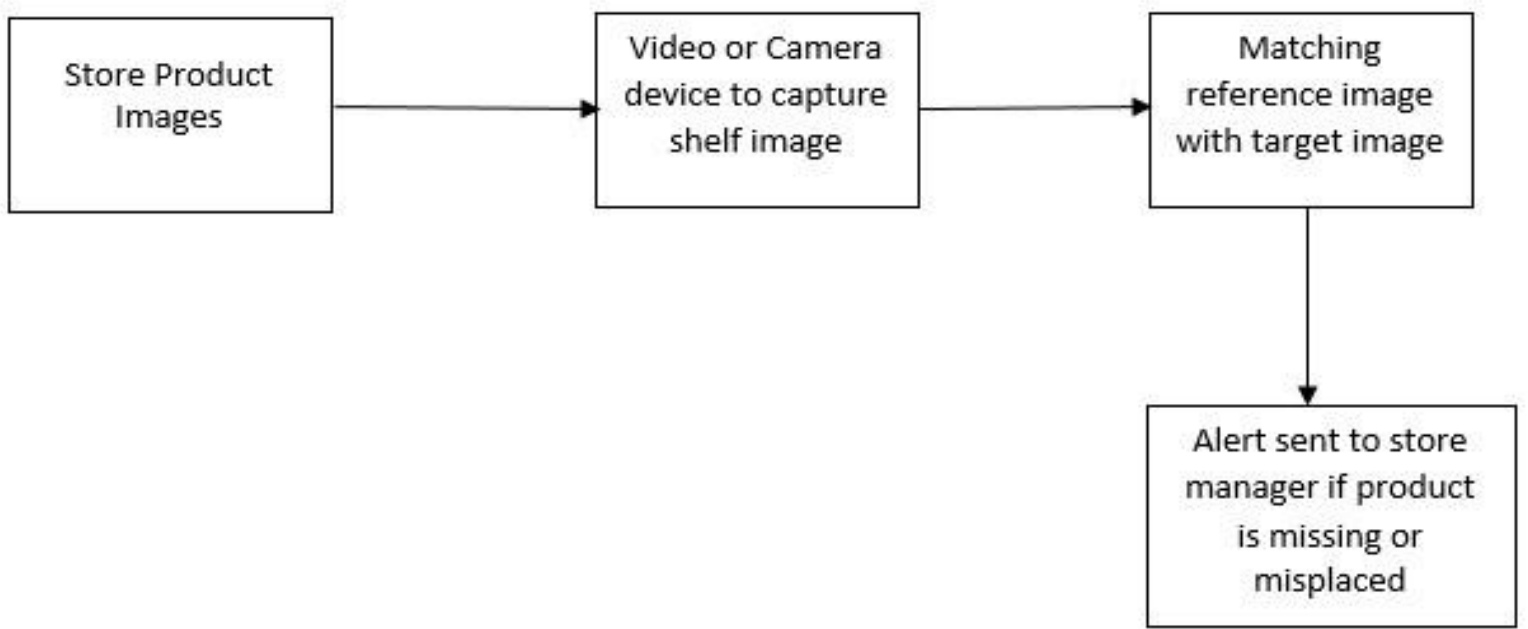

Fig 3: Flowchart of Proposed System

Future scope involves using an image processing tool that could help to develop an algorithm which can detect as well as count the total number of products on the shelf. It should be able to identify misplaced and missing products, as well as void spaces on the shelf

\section{REFERENCES}

[1] Joachim C.F. Ehrenthal, "A Service-Dominant Logic View of Retail On-Shelf Availability," Ph.D. dissertation, University of St.Gallen, St.Gallen, Switzerland, 2012.

[2] Kristie Jean Spielmaker, "On-Shelf Availability in Retailing: A Literature Review and Conceptual Model," Honours thesis, University of Arkansas, Fayettevilee, Arkansas, 2012.

[3] Anne-Sophie B., Gilles L. and Sandrine M., Assessing the Frequency and Causes of Out-of-Stock Events Through Store Scanner Data, Cahier de recherche du Groupe HEC, 2006.

[4] Shelf Availability Standards, Terms and DefinitionsHandbook, ECR Asia Pacific, 2013.

[5] Thomas G. and Daniel C. "A Comprehensive Guide To Retail Out-of-Stock Reduction In the Fast-Moving Consumer Goods Industry", USA, 2008.

[6] Andrew Mitchell. "Improving On-Shelf Availability", [White paper] SymphonyIRIGroup, 2012.

[7] Gerhard H. "Approaches to measuring on-shelf availability at the point of sale", [White paper] Roland Berger Strategy Consultants and ECR Europe, 2006.

[8] C. C. Chao, J. M. Yang and W. Y. Jen, Determining Technology Trends and Forecasts of RFID by Historical

Review and Bibliometric Analysis from 1991 to 2005, Technovation, Vol. 27, No. 5, 2007, pp. 268-279.
[9] David C. Wyld "24-KARAT PROTECTION: RFID and RETAIL JEWELRY MARKETING", International Journal of UbiComp (IJU), Vol 1, Num 1, January 2010.

[10] Jennifer Zaino "A Guide to RFID Apparel Retail Solutions", RFID Journal, 2011.

[11] Richard H. and Patricia D., Understanding RFID Technology within a Business Intelligence Framework, Intelligent Information Management, 2012, 4, 407-414.

[12] Michael A. Jones, David C. Wyld and Jeff W. Totten, "THE ADOPTION OF RFID TECHNOLOGY IN THE RETAIL SUPPLY CHAIN", The Coastal Business JournalVolume 4, Number 1.

[13] Susan A. Vowels "A STRATEGIC CASE FOR RFID: AN EXAMINATION OF WAL-MART AND ITS SUPPLY CHAIN", Proceedings of the Southern Association for Information Systems Conference, 2006.

[14] Trupti L., Rohan K., Anand P. and Akshay M., Comparative study of Barcode, QR-code and RFID System, Int.J.Computer Technology \& Applications, 2013,Vol 4 (5),817-821.

[15] Michael, K, \&McCathie, L, "The pros and cons of RFID in supply chain management, Proceedings of the International Conference on Mobile Business", 11-13 July 2005, 623629.Copyright IEEE 2005.

[16] Mobile Consumer Report: Understanding the Showrooming Shopper, Vibes Mobile Consumer Survey August 2012

[17] "Apparel Labeling: The Evolution of a Revolution", [White paper] Checkpoint 